\title{
Thermodynamic studies on Adsorption of lead (II) Ion from Aqueous Solution using Magnetite, Activated Carbon and Composites.
}

\section{*11ADEGOKE HI; ${ }^{2}$ ADEKOLA, FA; ${ }^{1}$ OLOWOOKERE, IT; ${ }^{1}$ YAQUB AL}

\author{
${ }^{I}$ Department of Chemistry, Faculty of Physical Sciences, University of Ilorin, P.M.B. 1515, Ilorin, Nigeria \\ ${ }^{2}$ Department of Industrial Chemistry, Faculty of Physical Sciences, University of Ilorin, P.M.B. 1515, Ilorin, Nigeria. \\ *Corresponding author, ihalimat@yahoo.com, +2347069365290
}

\begin{abstract}
Magnetite nanoparticles, activated carbon and their composite were synthesized in the laboratory and their adsorption capacities were tested for the removal of $\mathrm{Pb}$ (II) ion from aqueous solutions. Magnetite was prepared using co-precipitation method and the activated carbon prepared by chemical activation. The prepared adsorbents were characterized by some physico-chemical and spectroscopic methods. The instrumental techniques used for characterizing the adsorbents include Fourier Transform Infrared (FTIR), X -ray Fluorescence (XRF) and Scanning Electron Microscopy coupled with energy dispersive X-ray (SEM-EDX). The comparative adsorption of $\mathrm{Pb}$ (II) ion from aqueous solution onto different adsorbents was investigated using batch adsorption experiment at room temperature. The effects of initial metal ion concentration, contact time, adsorbent dosage, and temperature were evaluated. The activated carbon shows a structure like a honeycomb with a pattern of hollows and ridges, while the EDX shows an abundance of carbon. The results showed that maximum removal of $\mathrm{Pb}$ (II) ions was achieved with magnetite nanoparticles at a concentration of $100 \mathrm{mg} / \mathrm{L}$ within 60 minutes. The adsorption of $\mathrm{Pb}$ (II) on the all adsorbents best fitted the Langmuir adsorption isotherm based on its better regression coefficient. Kinetics result showed that the adsorption followed pseudo-second order perfectly implying chemisorption. Thermodynamic result revealed $\Delta \mathrm{G}$ values of $(-6.73$ to $-0.502 \mathrm{~kJ} / \mathrm{mol})$, depicting that the adsorption is feasible and spontaneous. Also, the reaction is endothermic as evident in the positive value of $\Delta \mathrm{H}(0.779$ to $22.815 \mathrm{~kJ} / \mathrm{mol}$ ) and positive value of $\Delta \mathrm{S}$ means there is an irregular increase in the randomness at the solid-solution interface of the adsorbents. The results obtained revealed that the adsorbents prepared can be used for the treatment of $\mathrm{Pb}$ (II)-based effluents.

(C) JASEM
\end{abstract}

\section{https://dx.doi.org/10.4314/jasem.v21i3.5}

Keywords: Adsorption, $\mathrm{Pb}$ (II) ion, Kinetics, Thermodynamics

The origin of the large quantities of aqueous effluents that contain high level of heavy metals is as a result of the extended use of metals and chemicals in the process industries and agricultural activities, which tends to pose difficult environmental disposal problems (Antunes et al., 2003). Heavy metals, which are not biodegradable (Vijayaraghavan et al., 2004) are therefore of great concern because they are being added to water, soil and air in increasing amounts. They are toxic to human health when consumed at relatively high amounts and may cause serious health problems upon long term exposures. This makes their effective removal from water sources within a reasonable cost, an important issue (Bready and Weil, 1999). Existing technologies for metal ion removal from waters are expensive; some of which include ion exchange resin, solvent extraction, electrolytic and precipitation processes, electro-dialysis and membrane technology (Stirk and Staden, 2000, Bishnoi et al., 2004). Other conventional technologies which have also been used ranged from granular activated carbon to reverse osmosis. These processes are however, not economically feasible for small scale industries prevalent in developing economies due to large capital investment (Horsfall and Spiff, 2004). Since most conventional methods are neither effective nor economical, especially when used for the reduction of heavy metal ions to low concentrations, new separation methods are required to reduce heavy metal concentrations to environmentally acceptable levels at affordable cost. Bio-removal has the potential to contribute to the achievement of this goal (Klimmek et al., 2001). Bio-removal is the accumulation and concentration of heavy metals from aqueous solutions using biological materials (Stirk and Staden, 2000).

Many adsorption materials have been investigated for the removal of heavy metals from water. Sorbents 
that have been studied include natural and artificial materials such as minerals (Amdur et al., 1991), carbon nano-material (Grossl et al., 1997) biosorbents (Moyes et al., 2000), and micro/nano structure metal oxides. Recently, emphasis has been on efficient, yet low cost and environmentally friendly adsorption. Micro/nano iron oxides such as goethite $(\alpha-\mathrm{FeOOH})$ and Hematite $\left(\alpha-\mathrm{Fe}_{2} \mathrm{O}_{3}\right)$ fall under this category. The benefits of using micro/nano materials may be derived from their increased affinity due to their high surface area and the presence of surface functional groups which makes them appropriate for heavy metal ions removal (Johnson, 1990). Iron - oxides are ideal for an efficient heavy metal ions removal due to their strong mechanical structure that can sustain water flow for extended periods of time and their low cost (Benjamin et al., 1996). Coconut husk was used as an adsorbent for the removal of $\mathrm{Cu}$ (II), Fe (III) and $\mathrm{Pb}$ (II) from industrial waste effluent (Abdulrasaq and Basiru, 2010). They reported that the adsorption of $\mathrm{Pb}$ (II) was found to be maximum $(94 \% \pm 3.2)$ at $\mathrm{pH} 5$, temperature of $100^{\circ} \mathrm{C}$, metal ion concentration of $30 \mathrm{ppm}$ and contact time of 30 minutes. $1 \mathrm{~g}$ of the adsorbent material was found to be optimal for all the metal ions; the Langmuir isotherm was found to be suitable for the adsorption of $\mathrm{Pb}$ (II) ion.

In this work, adsorption capacity of activated carbon, magnetite and their composites were investigated in the adsorption of $\mathrm{Pb}$ (II) ion from aqueous solution.

\section{MATERIALS AND METHOD}

Sample Preparation: The material used for activated carbon, coconut coirpith was collected from Ipata market, Ilorin, Kwara state, and was then carbonized, purified and activated.

Carbonization Process: A known amount of coconut coirpith was carbonized in a muffle furnace for 1 hour at $500{ }^{\circ} \mathrm{C}$, to convert the raw material to carbon, burn off volatile organic matter and also to increase its surface area, after which it was allowed to cool, then, weighed (Adebayo et al., 2015).

Purification Process: $100 \mathrm{~g}$ of carbonized sample was weighed into $1000 \mathrm{~mL}$ beaker and $500 \mathrm{~mL}$ of 0.5 $\mathrm{M} \mathrm{HCl}$ was added. The mixture was heated on a hot plate at a temperature of $200{ }^{\circ} \mathrm{C}$ for 2 hours then effervescence occurs. It was later cooled in a water bath then filtered. It was then washed to neutrality with deionized water (to remove the residual acid) and dried at $105{ }^{\circ} \mathrm{C}$ in an oven (Adebayo et al., 2015).
Activation Process: $50 \mathrm{~g}$ of purified carbon was weighed into $1000 \mathrm{~mL}$ beaker and $500 \mathrm{~mL}$ of $1 \mathrm{M}$ orthophosphoric acid was added. The solution was heated and stirred at $200{ }^{\circ} \mathrm{C}$ for 2 hours; it was allowed to cool, and then filtered, washed with deionized water, and oven dried at $105^{\circ} \mathrm{C}$.

Synthesis of Magnetite: $9.05 \mathrm{~g}$ of $\mathrm{FeSO}_{4} \cdot 7 \mathrm{H}_{2} \mathrm{O}$ (Iron sulphate heptahydrate) was dissolved in $500 \mathrm{~mL}$ of deionized water in a beaker. Then the system was homogenized in order to obtain the precipitate of iron oxide and oxyhydroxide. Then, $2 \mathrm{M} \mathrm{NaOH}$ was slowly added to the mixture until a $\mathrm{pH}$ of 11 was attained. After which the solution was left to precipitate for 24 hours and then poured into a dialysis tube held with a clip to remove the impurities and ions. It was dipped in a deionized water of known conductivity, the water is being changed and the conductivity checked daily until the same conductivity of the first day was attained. Then the pure solution was then fil,,CXtered using a filter membrane, dried in an oven at $100{ }^{\circ} \mathrm{C}$ for 15 minutes (Adegoke et al., 2010).

The equation of the reaction is stated below:

$3 \mathrm{FeSO}_{4} \cdot 7 \mathrm{H}_{2} \mathrm{O}+6 \mathrm{NaOH} \rightarrow \mathrm{Fe}_{3} \mathrm{O}_{4}+3 \mathrm{NaSO}_{4}+24 \mathrm{H}_{2} \mathrm{O}$
$+\mathrm{O}_{2}$ (i)
Synthesis of Composite: The composite was prepared by a method described by Worawan et al., 2011 in 1:2 ratio of iron-oxide and activated carbon powder dispersed in $0.1 \mathrm{M} \mathrm{HNO}_{3}$ solution vigorously stirred at $1800 \mathrm{rpm}$ for one hour. The mixture was aged for 24 hours at $80{ }^{\circ} \mathrm{C}$, and centrifuged. The precipitate was washed with deionized water to neutrality and then dried in an oven.

Sample Characterization: Fourier transform infrared spectroscopy (FTIR) spectra of the composite was obtained using a FTIR spectrophotometer (Shimadzu 8400 ) in wave number range of $3500-400 \mathrm{~cm}^{-1}$. The activated carbon sample was placed on a silicon substrate transparent to infrared, and the spectra were measured according to the transmittance method. The micrographs and elemental composition of prepared activated carbon were obtained using a (Carl Zeiss Ultra plus field emission electron microscope (FESEM) scanning electron microscopy-coupled with energy dispersed $\mathrm{x}$-ray.

Sorption Experiment: Stock solution of $\mathrm{Pb}$ (II) ion was prepared by dissolving $1.599 \mathrm{~g}$ of $\mathrm{Pb}\left(\mathrm{NO}_{3}\right)_{2}$ in deionized water in a standard volumetric flask of $1000 \mathrm{~mL}$ and made to the mark. It was from this solution that standards $(0-500 \mathrm{ppm})$ were prepared by serial dilution. 
Effect of Initial Concentration: $0.5 \mathrm{~g}$ of activated carbon, magnetite nanoparticle and the composite were contacted separately with $20 \mathrm{~mL}$ of $\mathrm{Pb}$ solutions $(100,200,300,400,500 \mathrm{ppm})$ in a bottle and were agitated in an orbital shaker for two hours, each mixture was then filtered separately and the filtrates were analyzed using Atomic Absorption Spectrophotometer (Bulk Scientific 210VP) (Baker $e t$ al., 2000).

Effect of Contact time: $0.5 \mathrm{~g}$ of activated carbon, magnetite and composite were weighed and dispersed in $20 \mathrm{~mL}$ of $\mathrm{Pb}$ (II) ion concentration that gave optimal adsorption and then shaken at different times of $20,40,60,80,100$, and 120 minutes. The mixture was then filtered and the filtrate was analyzed using Atomic Absorption Spectrophotometer

Effect of Adsorbent dosage: Different weight of the adsorbents $(0.1 \mathrm{~g}, 0.2 \mathrm{~g}, 0.3 \mathrm{~g}, 0.4 \mathrm{~g}$ and $0.5 \mathrm{~g})$ were contacted with the $20 \mathrm{~mL}$ of $\mathrm{Pb}$ (II) ion concentration that gave optimal adsorption and then shaken for 2 hours. The mixture was filtered, and the filtrate was then analyzed using Atomic Absorption Spectrophotometer (Bulk Scientific 210VP). This will enable us to know the exact adsorbent dose which will be sufficient for optimal removal of the metals (Adebayo et al., 2015).

Effect of Temperature: $0.5 \mathrm{~g}$ of activated carbon, magnetite and composite were weighed and dispersed in $20 \mathrm{~mL}$ of $\mathrm{Pb}$ (II) ion concentration that gave optimal adsorption and taken at different temperature of $30{ }^{\circ} \mathrm{C}, 35^{\circ} \mathrm{C}, 40{ }^{\circ} \mathrm{C}$, and $45^{\circ} \mathrm{C}$ and then shaken for 2 hours, the mixture was then filtered and the filtrate was analyzed using Atomic Absorption Spectrophotometer (Bulk Scientific 210VP).

The adsorption capacity was calculated using following formula:

$\mathrm{q}_{\mathrm{e}}=\frac{(C o-C e) V}{m}$

where $q_{\mathrm{e}}(\mathrm{mg} / \mathrm{g})$ is the equilibrium adsorption capacity, $C o$ and $C e(\mathrm{mg} / \mathrm{L})$ are the initial and equilibrium concentration of metal ions in solution, $V$ (L) is the volume, and $m(\mathrm{~g})$ is the amount of the adsorbent.

Adsorption Isotherm Studies: Adsorption is usually described through isotherms, that is, the amount of adsorbate on the adsorbent as a function of its pressure (if gas) or concentration (if liquid) at constant temperature. The quantity adsorbed is nearly always normalized by the mass of the adsorbent to allow comparison of different materials. Two adsorption isotherms, Langmuir and Freundlich models were tested using the experimental data of the equilibrium adsorption.

Langmuir Isotherm: The Langmuir isotherm is based on assuming a monolayer sorption onto a surface with a fixed number of well-defined sites (Langmuir, 1918); the equation is given below:

$\frac{C_{e}}{Q_{e}}=\frac{1}{K q_{\max }}+\frac{C_{e}}{q_{\max }}$

where, $K$ is the Langmuir constant $\left(\mathrm{L} \cdot \mathrm{mg}^{-1}\right)$ related to the apparent energy of adsorption, $q_{\max }$ is the quantity of adsorbate required to form a single monolayer per unit mass of adsorbent $\left(\mathrm{mg} \cdot \mathrm{g}^{-1}\right)$, considered as the maximum adsorption capacity and $Q_{e}$ is the amount adsorbed on unit mass of the adsorbent $\left(\mathrm{mg} \cdot \mathrm{g}^{-1}\right)$ when the equilibrium concentration is $C_{e}\left(\mathrm{mg} \cdot \mathrm{L}^{-1}\right)$ (Barkat et al. 2014).

Freundlich Isotherm: The Freundlich adsorption isotherm is an empirical equation used to describe heterogeneous system (Freundlich, 1907). The Freundlich isotherm is represented as:

$\mathrm{Q}_{\mathrm{e}}=\mathrm{K}_{\mathrm{f}} \cdot \mathrm{C}_{\mathrm{e}}{ }^{1 / n}$

where, $K_{f}$ is the Freundlich constant, which indicates the relative adsorption capacity of the adsorbent related to the bonding energy, and $n$ is the heterogeneity factor representing the deviation from linearity of adsorption and is also known as Freundlich coefficient. The Freundlich coefficients can be determined by linear regression from the plot of $\log Q_{e}$ versus $\log C e$ on the basis of the linearized equation

$\log \mathrm{Q}_{\mathrm{e}}=\log \mathrm{K}_{\mathrm{f}}+\frac{1}{n} \log \mathrm{C}_{\mathrm{e}}$

The plot of $\log Q_{e}$ as a function of $\log C_{e}$ at $293.15 \mathrm{~K}$ will lead us to determine the Freundlich constants $\left(\mathrm{K}_{\mathrm{f}}, 1 / \mathrm{n}\right)$.

Adsorption kinetics Study: Adsorption kinetics governs the rate of reaction, which determines the residence time and is one of the important characteristics defining the efficiency of an adsorbent. In order to investigate the mechanism of adsorption of $\mathrm{Pb}$ (II) ions unto the adsorbents, a pseudo second order kinetic model was applied to the experimental data.

The pseudo-second-order kinetic model has the linear form of (Sharma et al., 1991).

$\frac{t}{q_{t}}=\frac{1}{k_{2} q_{e}^{2}}+\frac{1}{q_{e}} t$

Where $\mathrm{q}_{\mathrm{e}}$ is the maximum adsorption capacity (mg.g ${ }^{-}$

$\left.{ }^{1}\right) ; \mathrm{t}$ is the time (minutes); $\mathrm{q}_{\mathrm{t}}$ is the amount adsorbed at time $\mathrm{t}\left(\mathrm{mg} \cdot \mathrm{g}^{-1}\right)$ and $\mathrm{k}_{2}$ is the equilibrium rate 
constant for the pseudo-second-order adsorption $\left(\mathrm{mg} \cdot \mathrm{g}^{-1} \mathrm{~min}^{-1}\right)$. The values of $\mathrm{k}_{2}$ and $\mathrm{q}_{\mathrm{e}}{ }^{2}$ were calculated from the plot of $\mathrm{t} / \mathrm{qt}$ versus $\mathrm{t}$.

Thermodynamic of Sorption: This helps to know if the adsorption process is an endothermic or exothermic in nature as well as the degree of freedom of the metal ion. Thermodynamic parameters such as changes in Gibbs free energy $\left(\Delta G^{0}\right)$, changes in enthalpy $\left(\Delta \mathrm{H}^{\circ}\right)$ and change in entropy $\left(\Delta \mathrm{S}^{\circ}\right)$ for the adsorption process were calculated using the following equations (Akpomie and Dawodu, 2015).

$\Delta \mathrm{G}=-\mathrm{RT} \ln \mathrm{K}$

$\ln \mathrm{K}=\Delta \mathrm{S} / R_{R}-\Delta \mathrm{H} / R T$

where $\mathrm{T}$ is the temperature $(\mathrm{K}), \mathrm{R}$ is the ideal gas thermodynamic equilibrium constant, $\mathrm{Ca}(\mathrm{mg} / \mathrm{L})$ is the concentration of metal ion adsorbed and $\mathrm{Ce}$ $(\mathrm{mg} / \mathrm{L})$ is the equilibrium concentration of metal ion in solution. The values of $\Delta \mathrm{H}^{\mathrm{o}}$ and $\Delta \mathrm{S}^{\mathrm{o}}$ were calculated from the slope and intercept of the linear plot of $\operatorname{lnK}$ versus $1 / \mathrm{T}$.

\section{RESULTS AND DISCUSSION}

During precipitation of magnetite, the light yellow $\mathrm{Fe}^{2+}$ solution turned to green and then black when $\mathrm{NaOH}$ was added to it as a result of the combination of both iron oxide and iron (II) oxyhydroxide particles, the precipitate turned to black after 24 hours. A fine textured precipitate with a $\mathrm{pH}$ of 7.8 was obtained after impurities were removed within 7 days of dialysis.

constant $(8.314 \mathrm{~J} / \mathrm{molK}), \quad \mathrm{K}=\left(\frac{C a}{C e}\right)$ is the

Table 1: Physico-chemical properties of the synthesized samples

\begin{tabular}{llll}
\hline Properties & Activated carbon & Magnetite & Composite \\
\hline Colour & Black & Black & Black \\
Texture & Fine & Fine & Fine \\
Magnetic strength & Not magnetite & Very magnetic & Not magnetic \\
Bulk density & $0.632 \mathrm{~g} / \mathrm{ml}$ & $0.655 \mathrm{~g} / \mathrm{mL}$ & - \\
$\mathrm{pH}$ & 6.3 & 7.8 & 4.80 \\
\hline
\end{tabular}

The colour of magnetite is black which is in line with the colour for different iron oxides reported by Schwertmann, 1991. The activated carbon and composite are also black in colour. The $\mathrm{pH}$ of the adsorbent is the degree of acidity or basicity of that adsorbent and depends on number of factors which include method of preparation, inorganic matter content, chemically active oxygen groups on its surface as well as the kind of treatment to which the adsorbent was subjected to (Gan et al., 2004). The $\mathrm{pH}$ of the adsorbents are in the range $4.80-7.8$. The $\mathrm{pH}$ of activated carbon is 6.3 , this could be linked to the activating reagent, orthophosphoric acid used in the preparation. The $\mathrm{pH}$ of magnetite is 7.8 which imply that it is basic. All the adsorbent are fine in texture. Magnetite nanoparticle is magnetic in nature while the others are non-magnetic. The bulk densities for the adsorbents are in the range $0.632-0.655 \mathrm{~g} / \mathrm{ml}$. The values of bulk density obtained for the adsorbents revealed that the sample might be of great potential for waste water treatment as their bulk densities are higher than $0.25 \mathrm{~g} / \mathrm{ml}$ which is the minimum requirement for commercial adsorbents (Denver, 1991).

Table 2: Elemental composition of the Activated carbon (AC)

\begin{tabular}{lll}
\hline Elements & $\mathrm{Wt} \%$ & $\mathrm{Wt} \%$ Sigma \\
\hline $\mathrm{C}$ & 71.84 & 0.39 \\
$\mathrm{O}$ & 26.90 & 0.38 \\
$\mathrm{Si}$ & 0.51 & 0.02 \\
$\mathrm{P}$ & 0.45 & 0.03 \\
$\mathrm{~K}$ & 0.10 & 0.02 \\
$\mathrm{Ca}$ & 0.20 & 0.02 \\
Total & 100.00 & \\
\hline
\end{tabular}

It can be seen from table 2 that the basic composition of the activated carbon obtained from XRF analysis is carbon $(71.84 \%)$. 


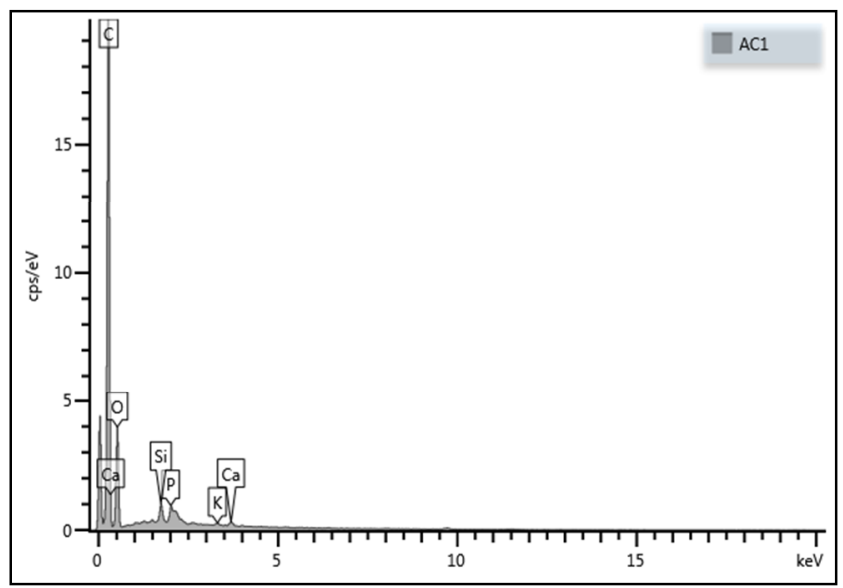

Fig. 1: Elemental composition shown by the EDX

The result of the EDX revealed that carbon has the highest percentage in the prepared activated carbon; this result is supported by the XRF result.

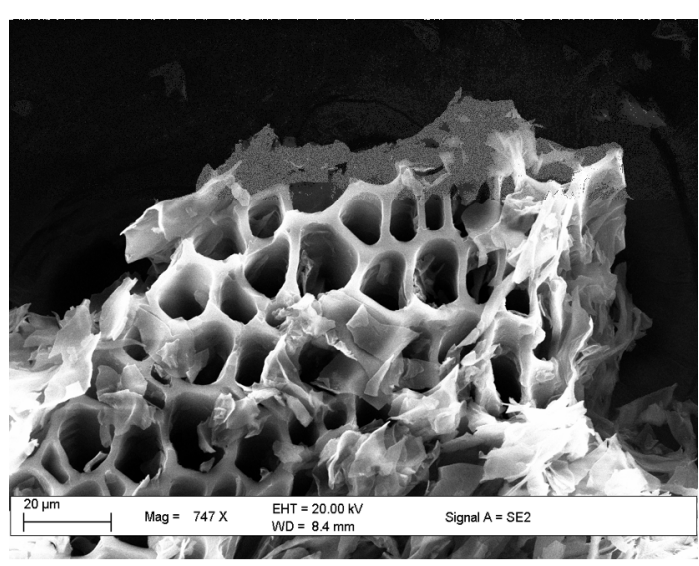

Fig. 2: SEM image of the AC at X747

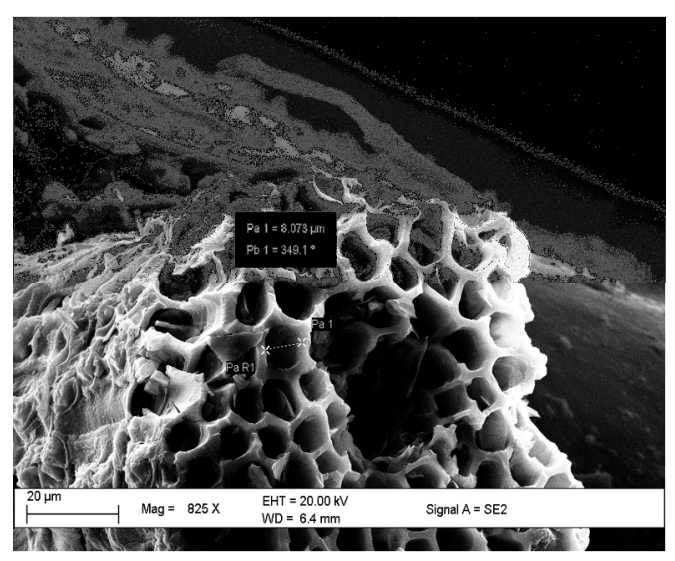

Fig. 3: SEM image of the AC at X825

The scanning electron micrographs of the activated carbon at different magnifications are presented in Figs 2 and 3 above. This allows evaluation of the surface morphology and the overall structure of the particles. The morphology of the clay revealed a very porous structure with close resemblance to a honeycomb with patterns of hollows and ridges conjoined together. The presence of pores in the activated carbon would greatly influence the uptake of the metal ions from the solution (Akpomie and Dawodu, 2015). While the elemental composition result from EDX shows an abundance of carbon with over $71 \%$ weight, Oxygen of about $22 \%$; other elements are in trace amounts. 
Table 3: The FTIR interpretation for the adsorbents

\begin{tabular}{|c|c|c|}
\hline Functional Group & $\begin{array}{l}\text { Characteristics } \\
\text { Absorptions }\left(\mathrm{cm}^{-1}\right)\end{array}$ & Intensity \\
\hline $\begin{array}{l}\text { Alcohol } \\
\text { O-H } \\
\text { Alkane }\end{array}$ & 3427.51 & Strong, and Broad \\
\hline C-H & 2856.58 & Strong \\
\hline $\begin{array}{l}\mathbf{C} \sim \mathbf{H} \\
\text { Amide }\end{array}$ & 1377.17 & Variable and Broad \\
\hline & 3427.51 & Strong and Broad \\
\hline N-H & 3427.51 & Strong and Broad \\
\hline $\begin{array}{l}\text { C-N } \\
\text { Aromatic }\end{array}$ & $1122.57,1269.16$ & Weak and Broad \\
\hline $\begin{array}{l}\mathbf{C}=\mathbf{C} \\
\text { Carbonyl }\end{array}$ & $1467.83,1519.91$ & Medium, Weak and Variable \\
\hline $\begin{array}{l}\mathbf{C}=\mathbf{O} \\
\text { Ether }\end{array}$ & 1710.86 & Weak, Medium and Sharp \\
\hline $\begin{array}{l}\text { C-O } \\
\text { Nitro }\end{array}$ & $1039.63,1122.57$ & Medium and Broad \\
\hline $\begin{array}{l}\text { N-O } \\
\text { Magnetite }\end{array}$ & 1377.17 & Broad and Medium \\
\hline $\begin{array}{l}\text { (Fe-O) } \\
\text { Alkyl-Halide }\end{array}$ & $\begin{array}{l}576.72 \\
576.72\end{array}$ & $\begin{array}{l}\text { Strong and Medium } \\
\text { Weak and Medium }\end{array}$ \\
\hline
\end{tabular}

The summary of peaks obtained from the FTIR spectra is shown in Table 3, a broad absorption band at $3427.51 \mathrm{~cm}^{-1}$ is due to the $\mathrm{O}-\mathrm{H}$ stretching frequency. The absorption band at $576.72 \mathrm{~cm}^{-1}$ indicates the stretching frequency of Fe-O due to $\mathrm{H}_{2} \mathrm{O}$ (Liu et al, 2010). This characteristic is attributed to magnetite $\left(\mathrm{Fe}_{3} \mathrm{O}_{4}\right)$ particle. The $\mathrm{C}-\mathrm{H}$ stretching vibration at $2856.58 \mathrm{~cm}^{-1}$ indicates the presence of alkane $\left(\mathrm{sp}^{3}\right)$ stretching vibration functional group. The $\mathrm{C}=\mathrm{C}$ stretching vibrations at $1467 \mathrm{~cm}^{-1}$ is assigned to alkenes and aromatic stretching vibration functional groups. The FTIR spectra obtained were in agreement with the results reported in the study carried out on commercial granular activated carbons by Jung et al, 2001. This is also in agreement with the work of Tan et al. 2008.

Results of Batch Adsorption Experiments: Effect of initial concentration: the plots of the amount of $\mathrm{Pb}$
(II) ion adsorbed on the adsorbents ( $0.5 \mathrm{~g}$ each) from $20 \mathrm{ml}$ solutions for different initial concentrations (100-500ppm) of $\mathrm{Pb}$ (II) ion is shown in fig. 4. The initial concentration of adsorbate plays an important role as a given mass of the adsorbent can adsorb only a fixed amount of the solute. The more concentrated the solution, the lower the amount of metal ion that a given mass of adsorbent can adsorb (Ferda and Serin, 2012). Consequently, as concentration increases, the adsorption of $\mathrm{Pb}^{2+}$ ions onto the adsorbent was observed to decrease. However, an optimum concentration whereby there was no significant decrease in $\mathrm{Pb}$ adsorption was observed at 100ppm for all the adsorbents. Comparatively, the amount of $\mathrm{Pb}$ adsorbed by magnetite and its composite (with activated carbon) is relatively of higher capacity than that of the activated carbon only.

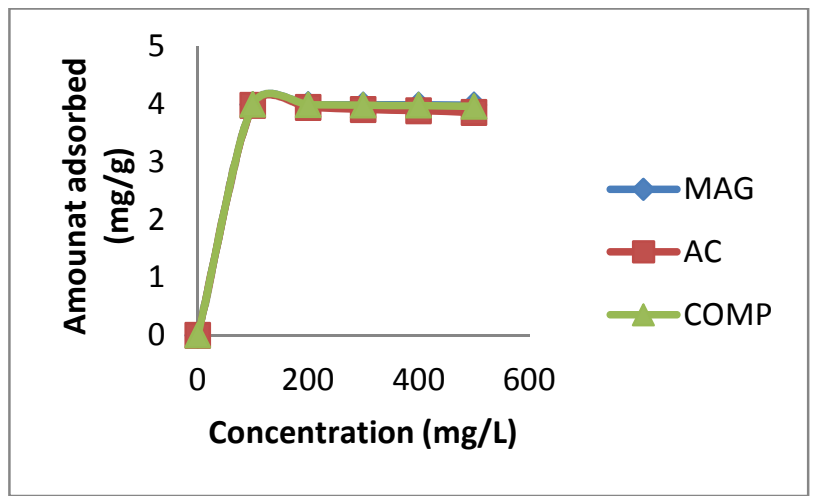

Fig. 4: Effect of initial concentration on $\mathrm{Pb}$ (II) ion adsorption onto activated carbon (AC), magnetite (MG), and composite (COMP) 
Effect of contact time: A rapid uptake of pollutants and establishment of equilibrium in a short period signifies the efficiency of the adsorbent for its use in water treatment (Ferda and Serin, 2012). The effect of contact time on adsorption of $\mathrm{Pb}$ (II) ions is represented in fig. 5, the plot showed a very high rate of adsorption of $\mathrm{Pb}$ (II) ions $(110.68 \mathrm{mg} / \mathrm{g}$ ) onto magnetite within 60 minutes, while the composite was able to achieve maximum adsorption of 79.22 $\mathrm{mg} / \mathrm{g}$ at 100 minutes of contact. However, activated carbon when compared with magnetite and composite showed a relatively low adsorption capacity of $11.50 \mathrm{mg} / \mathrm{g}$ even after 120 minutes of contact with the adsorbate

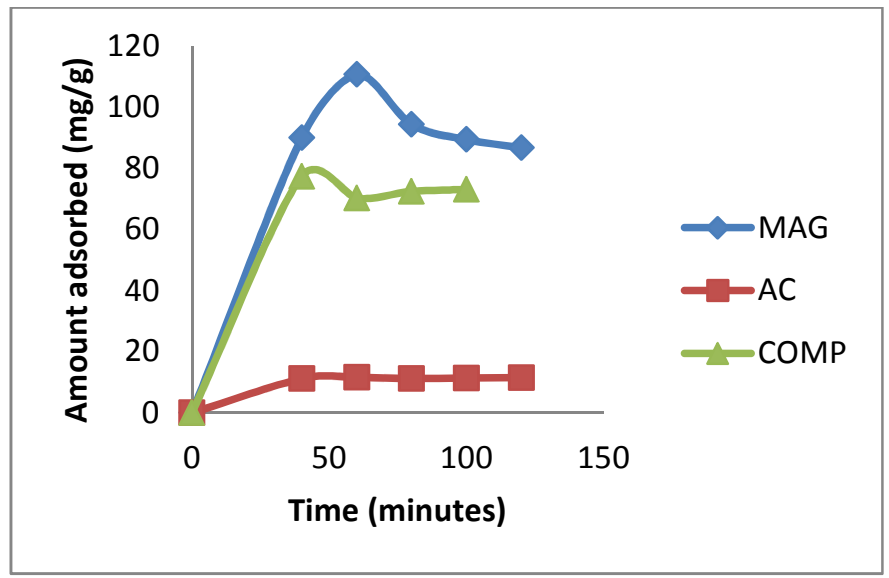

Fig. 5: Effect of contact time on $\mathrm{Pb}$ (II) ions adsorption onto activated carbon (AC), magnetite (MG), and composite (COMP)

Effect of Adsorbent dosage: Adsorbent dose is known to have a great effect on adsorption studies. The amount of adsorbent available in solution determines the number of active binding sites available for metal ions (Zafar et al., 2007). Fig. 6 shows the effect of adsorption of $\mathrm{Pb}(\mathrm{II})$ ions on different weights of activated carbon, magnetite and their composite when a fixed concentration of $\mathrm{Pb}$ (II) ions was contacted with the adsorbents for 100 minutes. From the graph, it can be seen that increase in adsorbent dosage (from
0.1 gram to 0.5 gram) does not lead to an increase in adsorption, rather, there was steady decrease in the amount of $\mathrm{Pb}$ (II) ion adsorbed on all the adsorbents (activated carbon, magnetite, composites). It is however believed that at 0.1 gram of the adsorbents, the active site available for binding has been occupied by the metal ions such that further increase in the adsorbent dosage will not bring about appreciable adsorption

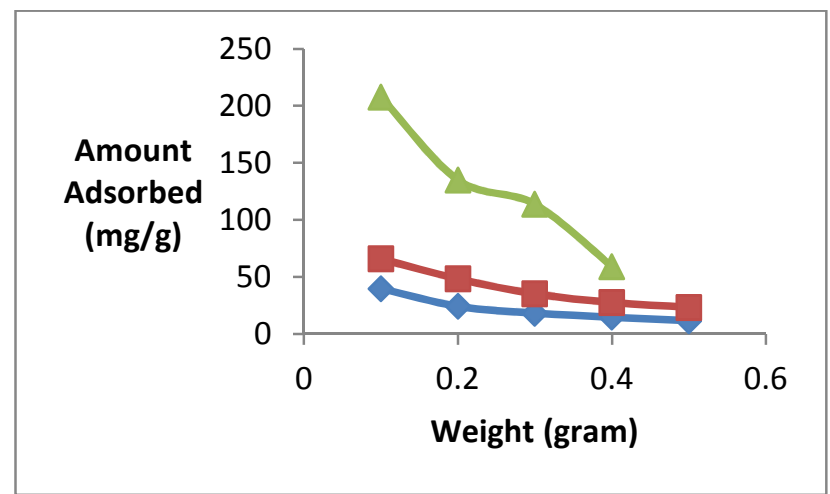

Fig. 6: Effect of activated carbon (AC), magnetite (MG), and composite (COMP) dosage on $\mathrm{Pb}$ (II) ions adsorption

Effect of Temperature: The result of effect of temperature on the adsorption of $\mathrm{Pb}$ (II) ions were shown in Fig 7. From the result, it is evident that there is an increase in the amount adsorbed as the temperature increases from $30{ }^{\circ} \mathrm{C}$ to $45^{\circ} \mathrm{C}$. From the result it can be deduced that the adsorption was endothermic in nature. Since adsorbent is porous in nature and possibilities of diffusion of adsorbate 
cannot be ruled out. Therefore, the rise in temperature favoured the adsorbate transport into the pores of adsorbent as related to the work of Manjeet et al., 2009. The amount adsorbed by the activated carbon increased from $11.22 \mathrm{mg} / \mathrm{g}$ to $11.84 \mathrm{mg} / \mathrm{g}$ as the temperature increased from $30{ }^{\circ} \mathrm{C}$ to $45{ }^{\circ} \mathrm{C}$. The same trend was observed for composite as adsorption increased from $66.56 \mathrm{mg} / \mathrm{g}$ at $30{ }^{\circ} \mathrm{C}$ to $80.45 \mathrm{mg} / \mathrm{g}$ at $45{ }^{\circ} \mathrm{C}$. Also, adsorption on magnetite was dependent on temperature as the amount of $\mathrm{Pb}$ (II) ions adsorbed increased from $107.53 \mathrm{mg} / \mathrm{g}$ to $111.58 \mathrm{mg} / \mathrm{g}$ as the temperature increases.

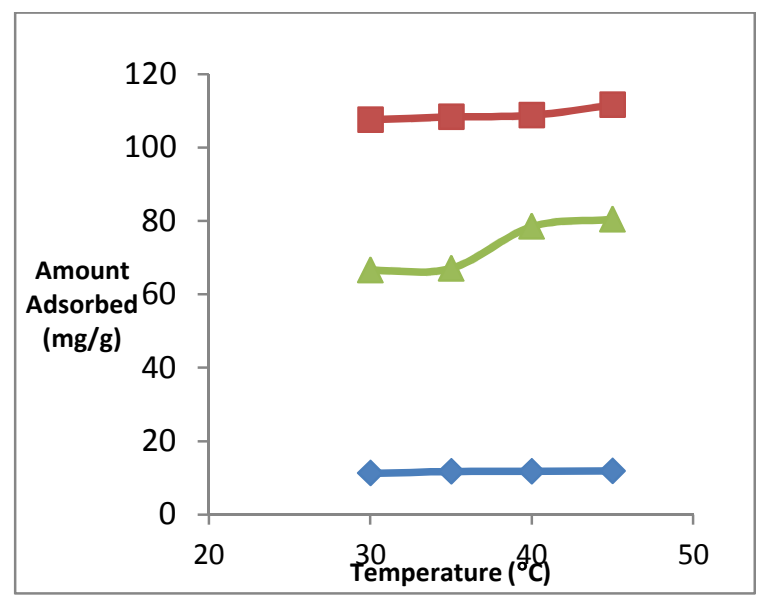

Fig. 7: Effect of temperature on $\mathrm{Pb}$ (II) ions adsorption onto activated carbon (AC), magnetite (MG), and composite (COMP)

Adsorption Isotherm: Adsorption isotherms can be used to relate the adsorbate concentration in the bulk and the adsorbed amount at the interface at equilibrium. In this regard, the Langmuir and Freundlich isotherms were applied to the experimental data and their parameters are given in Table 4.

The values of the linear correlation, $\mathrm{R}^{2}$, of each isotherm equation, when fitted to the experimental data obtained from the adsorption of $\mathrm{Pb}^{2+}$ by the adsorbents are presented. However, higher values of $\mathrm{R}^{2}$ were obtained when the experimental data were fitted into Langmuir isotherms with $\mathrm{R}^{2}$ value of 0.9998, 1 and 1 for activated carbon, magnetite and composite respectively. Therefore, the higher correlation coefficients of linearized Langmuir equation indicates that Langmuir isotherm fitted the experimental data better as obtained from the regression coefficient. Thus, the description of the adsorption of $\mathrm{Pb}$ (II) ions onto the adsorbents indicates that the coverage of the adsorption site was in the form of monolayer coverage (Al-deqsy et al., 2006).

The result of the experimental data fitted with the Freundlich isotherm revealed the correlation coefficient to be in the range $0.807-0.9723$ for all adsorbent types. 


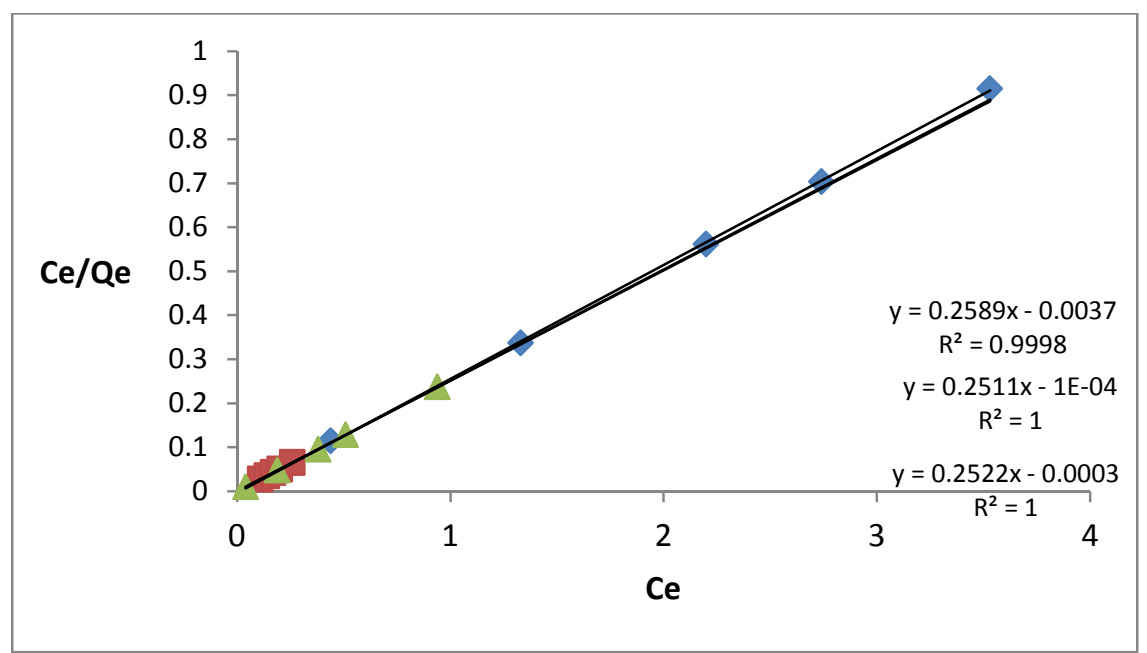

Fig 8: Langmuir Adsorption Isotherm for Activated carbon, Magnetite and Composite.

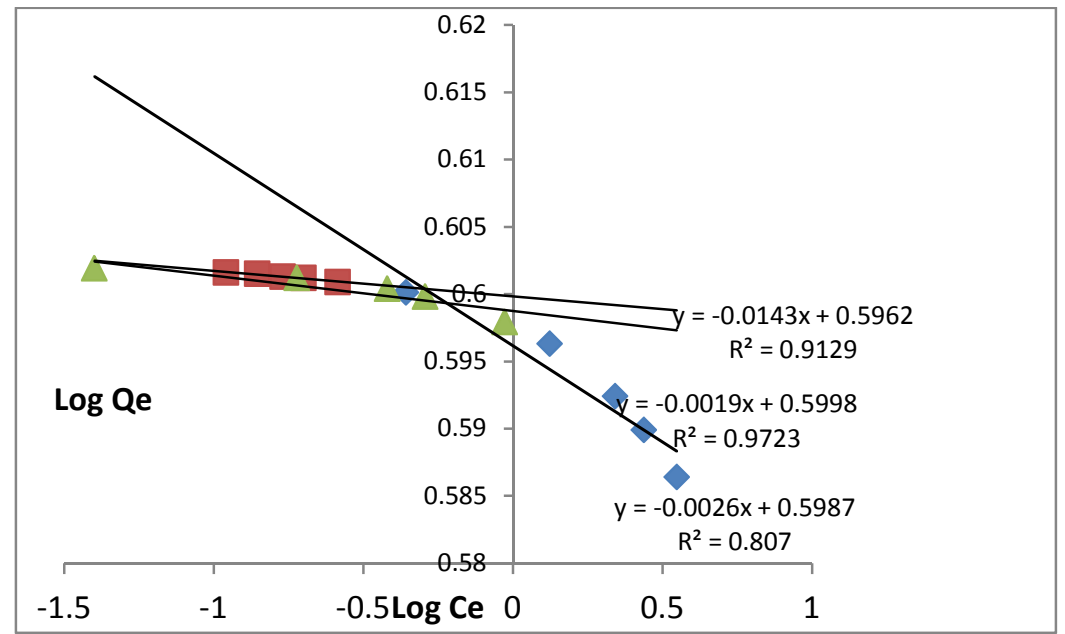

Fig. 9: Freundlich Adsorption Isotherm for Activated carbon, Magnetite and Composite.

Table 4: Langmuir and Freundlich Model parameters

\begin{tabular}{lllll}
\cline { 1 - 3 } Parameter & $\mathrm{k}(\mathrm{L} / \mathrm{mg})$ & $\mathrm{q}_{\max }$ & \multicolumn{2}{l}{$\mathrm{R}^{2}$} \\
\cline { 1 - 3 } Langmuir Isotherm(AC) & -69.98 & 3.862 & 0.9998 & \\
Langmuir Isotherm(MAG) & -2511.30 & 3.982 & 1 & \\
Langmuir Isotherm(COMP) & -840.69 & 3.965 & 1 & \\
& $\mathrm{~K}_{\mathrm{f}}$ & $1 / \mathrm{n}$ & $\mathrm{n}$ & $\mathrm{R}^{2}$ \\
& 3.946 & -0.0143 & -69.93 & 0.9129 \\
Freundlich Isotherm(AC) & 3.979 & -0.0019 & -526.32 & 0.9723 \\
Freundlich Isotherm(MAG) & 3.979 & -0.0026 & -384.62 & 0.807 \\
Freundlich Isotherm(COMP) & 3.969 & & &
\end{tabular}

Result of Adsorption Kinetics: From fig. 10, it can be deduced that the pseudo second-order kinetics model represented the adsorption of $\mathrm{Pb}^{2+}$ ion on all the adsorbents with a correlation co-efficient $\left(\mathrm{R}^{2}\right)$ very close to linear suggesting that the adsorption is likely to be a chemisorption process. 


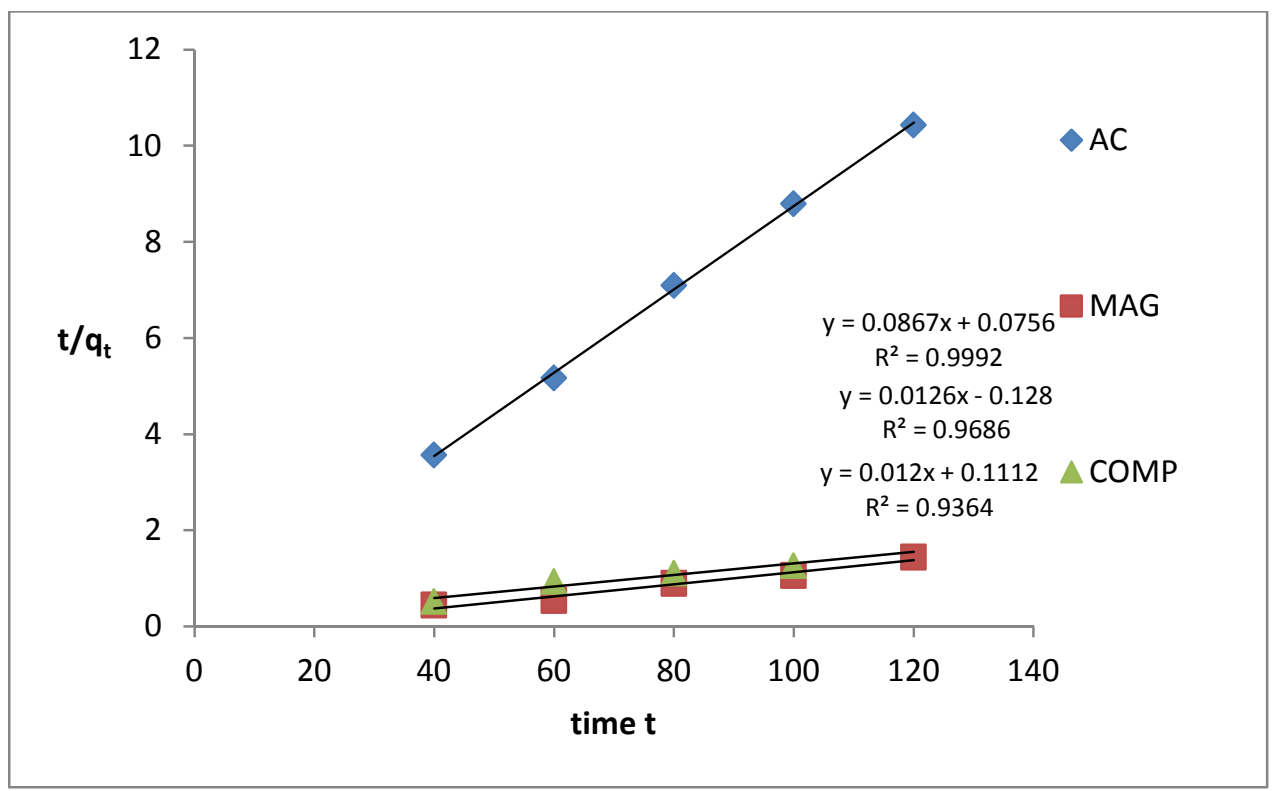

Fig 10: Pseudo-second order for Activated carbon, Magnetite and Composite.

Table 5: Pseudo-second order parameters

\begin{tabular}{llll}
\hline Parameters & $\mathbf{q}_{\mathbf{e}}$ & $\mathbf{k}_{\mathbf{2}}$ & $\mathbf{R}^{\mathbf{2}}$ \\
\hline AC & 11.534 & 0.099 & 0.9992 \\
MAG & 79.365 & -0.00124 & 0.9686 \\
COMP & 83.333 & 0.00129 & 0.9364 \\
\hline
\end{tabular}

Results of Thermodynamics Study: The influence of temperature of solution on the amount of $\mathrm{Pb}$ (II) ions removed from solution unto the adsorbents is presented in Fig. 11. From table 6, the positive values of heat of adsorption $\Delta \mathrm{H}$ for Magnetite and composite suggested that the adsorption of metal ions is endothermic, which is supported by the increased adsorption of metal ions with increase in temperature. As temperature increases, the metal ion acquire more energy to overcome the energy barrier between the metal and adsorbents, simultaneously creating more additional adsorption sites on the adsorbent surface due to dissociation of some of the surface components on adsorbents (Akpomie and Dawodu, 2015). Also, the positive values of $\Delta S$ for all the adsorbents indicated an increase in randomness at the solid-solution interface during the adhesion of the adsorbate on the active site of the adsorbent. $\Delta \mathrm{G}$ was negative for all the adsorbents from 303 up to $318 \mathrm{~K}$ respectively depicting that the adsorption is favourably spontaneous and feasible 


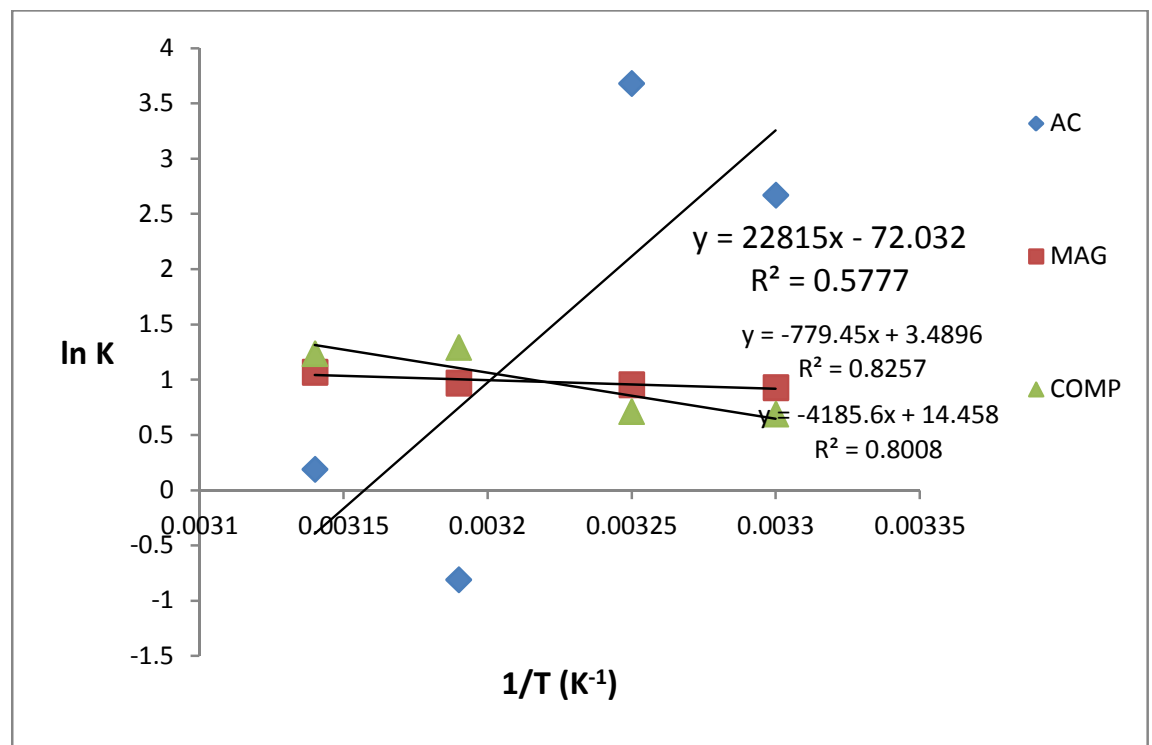

Fig 11: Plots of $\ln \mathrm{K}$ versus 1/T for Activated carbon, Magnetite and Composite.

Table 6: Shows the calculated values for $\Delta \mathrm{H}, \Delta \mathrm{S}$, and $\Delta \mathrm{G}$

\begin{tabular}{lllllll}
\hline & & \multicolumn{5}{c}{$\Delta \mathrm{G}(\mathrm{kJ} / \mathrm{mol})$} \\
\cline { 4 - 6 } Samples & $\Delta \mathrm{H}(\mathrm{kJ} / \mathrm{mol})$ & $\Delta \mathrm{S}(\mathrm{kJ} / \mathrm{molK})$ & $303 \mathrm{~K}$ & $308 \mathrm{~K}$ & $313 \mathrm{~K}$ & $318 \mathrm{~K}$ \\
\hline Activated carbon & 22.815 & 0.599 & -6.73 & -9.42 & 2.11 & -0.502 \\
Magnetite & 0.779 & 0.029 & -2.34 & -2.45 & -2.52 & -2.82 \\
Composite & 4.185 & 0.120 & -1.73 & -1.82 & -3.36 & -3.26 \\
\hline
\end{tabular}

Conclusion: The adsorption efficiencies of different adsorbents (Magnetite nanoparticles, activated carbon and their composite) prepared in the laboratory has been studied in the laboratory. The prepared adsorbents were characterized by some physicochemical and spectroscopic methods such as Fourier Transform Infrared (FTIR), X -ray Fluorescence (XRF) and Scanning Electron Microscopy coupled with energy dispersive X-ray (SEM-EDX). The adsorption experimental data were fitted into different adsorption isotherm. The adsorption of $\mathrm{Pb}$ (II) on all adsorbents best fitted the Langmuir adsorption isotherm. The kinetic and thermodynamic results revealed that the adsorption follows the pseudo-second order model and spontaneous in nature. The results obtained revealed that the prepared adsorbents can be used for the treatment of $\mathrm{Pb}$ (II) -based waste water.

\section{REFERENCES}

Abdulrasaq Oyedeji O. and Basiru Osinfade G. (2010). Removal of copper (II), iron (III) and lead (II) ions from Mono-component Simulated Waste Effluent by Adsorption on Coconut Husk. Afri. J. Environ. Sci. Techn. 4(6): 382-387.

Adebayo, G. B., Adegoke, H. I., Jamiu, W., Balogun, B. B., Jimoh A. A., (2015). Adsorption of Mn(II) and $\mathrm{Co}$ (II) Ions From Aqueous Solution Using
Maize Cob Activated Carbon: Kinetics and Thermodynamics Studies. J. Appl. Sci. Environ. Manage. 19(4): 737 - 748.

Adegoke H. I., Adekola F. A., Attah A. A., (2011). Adsorption of lead (II) from aqeous solution using Magnetite, $34^{\text {th }}$ Annual Chemical Society International Conference Proceedings Phy, 6469.

Akpomie K. G., Dawodu F. A., (2015), Potential of a low-cost bentonite for heavy metal abstraction from binary component system, Beni-suef university J. Bas. Appl. Sci., 4: 1 - 13.

Al-deqsy, S., El-barhouthi, M.I, Issa, A.A., Khaisheh, M.A., Walker, G.M., (2006). Sorption of Zn(II), $\mathrm{Pb}$ (II) and $\mathrm{Co}$ (II) using natural sorbents: Equil. Kinet. Stud. Wat. Res. 40: 26-45.

Amdur, M. O., Doull, J. and Klaasen, C. (1991). Toxicology, the Basic science of poisons, Pergamon press, New York, 23, $639-643$.

Antunes W.M., Luna A.S., Henriques C.A., Da Costa A.C.A., (2003). An evaluation of copper biosorption by abrown seaweed, under optimized conditions. Electronic J. Biotech., 6(3): 174-184. 
Baker A.S.J., Brown A.S.C., Edwarda, M.A., Hargeaves J.S.J., and Pankhurst Q.A., (2000). A structural study of samples prepared from sulfate Goethite precursors the generation of axial mesoporous voids. J. Mater, Chem., 10: 761 766.

Barkat, M., Chegrouche, S., Mellah, A., Bensmain, B., Nibou, D. and Boufatit, M., (2014). Application of Algerian Bentonite in the Removal of Cadmium (II) and Chromium (VI) from Aqueous Solutions. J. Surf. Eng. Mater. Adv. Technol., 4: 210 - 226.

American Water Works Association (1991)

Benjamin, M. M., Slettern, R. S., Bailey, R. P. and Bennett, T. (1996). Sorption and Filteration of metals using iron-coated sand". Water Res., 30, $2609-2619$.

Bishnoi N.R., Bajaj M., Sharma N., Gupta A., (2004). Adsorption of chromium (VI) ion on activated rice husk, carbon and activated alumina. Bioresour Technol., 91: 305 - 307.

Bready, N, and Weil, R, (1999). The nature and properties of soils. Prentice Hall, Upper saddle River, New Jersey, 21, 74 - 92.

Denver Co (1991) American Water Works Association (AWWA) ANSI/AWWA B, 1991.604-690.

Ferda G., and Serin D. S., (2012). Adsorption study on orange peel: Removal of $\mathrm{Ni}(\mathrm{II})$ ions from aqueous solution. Afri. J. Biotechnol., 11(5): $1250-1258$.

Freundlich, H.M.F., (1907). Uber Die Adsorption in Losungen. Zeitschrift für Physikalische Chemie, $57,385-470$.

Gan, Q, Allen, S.J. and Mathew, R. (2004). Activation of waste MDF sawdust charcoal and its reactive dye adsorption characteristics. Waste Management, 28(8), 841-848.

Grossl, P. R., Eick, M., Sparks, D. L., Goldberg, S. and Aimsworth, C. C., (1997). Arsenate and chromate retention mechanism on Geothite. Environ. Sci. Technol., 31: 321 - 326.

Horsfall M., and Spiff A.I., (2004). Studies on the Effect of $\mathrm{pH}$ on the Sorption of $\mathrm{Pb}^{2+}$ and $\mathrm{Cd}^{2+}$ ions from aqueous Solutions by Caladium bicolor (Wild cocoyam) Biomass. Electronic J. Biotech., 7(3): 313 - 323 .

Johnson, B. B., (1990). Effect of pH, Temperature and Concentration on the adsorption of Cadmium on Goethite. Environ Sci. technol., 24: $112-118$.

Jung M., Ahn K ., Lee Y., Kim K., Rhee J., Park J.T. and Paeng K.(2001) Adsorption

characteristics of phenol and chlorophenols on granular activated carbon (GAC). Microchemical Journal, 70 123-131.

Klimmek S., Stan H.J., Wilke A., Bunke G., Buchholz R., (2001). Comparative analysis of the biosorption of cadmium, lead, nickel and zinc by Algae. Environ. Sci. Technol., 35: 4283-4288.

Langmuir, I., (1918). The Adsorption of Gases on Plane Surfaces of Glass, Mica and Platinu. $J$. Am. Chem. Soc., 40: 1361 - 1403.

Liu Z., Zhang F-S., Sasai R. (2010) Arsenate removal from water using $\mathrm{Fe}_{3} \mathrm{O}_{4}$-loaded activated carbon prepared from waste biomass. Chemical Engeering Journal, 160 57-62.

Manjeet B., Diwan S., Garg V.K., and Pawan R. (2009). Use of Agricultural Waste for the Removal of Nickel Ions from Aqueous Solutions: Equilibrium and Kinetics Studies. Int. J. Civil Environ. Eng. 1(2): 108 -114.

Moyes, L. N., Parkman, R. H., Charmock, T. M., Vaughan, D. J., Livens, F. R., Hughes, C. R. and Braithwaite, A., (2000). Uranium Uptake from Aqueous Solution by Interaction with Goethite, Lepidocrocite, Muscovite and Mackinawitw: An X-ray Absorption Spectroscopy Study. Environ. Sci Technol., 34: 1062 - 1068.

Schwertmann, U. and Cornell, R. M. (1991) Iron oxide in the laboratory. Weinheim VCH Verlag, $117 \mathrm{pp}$.

Sharma Y.C., Prasad G., and Rupainwar D.C., (1991). Removal of $\mathrm{Ni}$ (II) from aqueous solutions by sorption. Int. J. Environ. Studies, 37: 183 - 191.

Stirk W.A., and Staden J.V., (2000). Removal of heavy metals from solution using dried brown seaweed material. Botanica Marina, 43: 467 473.

Tan I.A.W., Ahmad A.L., and Hameed B.H. (2008) Preparation of activated carbon from coconut ADEGOKE HI; ADEKOLA, FA; OLOWOOKERE, IT; YAQUB AL 
husk: Optimization study on removal of 2,4,6trichlorophenol using response surface methodology. Materials, 153, 709-717

Vijayaraghavan K., Jegan J.R., Palanivelu K., Velan M., (2004). Copper removal from aqueous solution by marine green algae (Ulva reticulata) Electronic J. Biotechnol. 61 - 71 .
Worawan .N, Chitnarong .S, Chantarapom .P, (2011). Magnetic composites prepared from palm shellbased carbon and application for recovery of residual oil from POME. J. Environ. Manage. $92,472-479$.

Zafar M. N., Nadeem R., Hanif M. A., (2007). Biosorption of nickel from protonated rice bran. J. Hazard Mater. 143: 478 - 485. 